\title{
ASSESS THE LEVEL OF SELF-ESTEEM AMONG ADOLESCENTS AT GOVERNMENT HIGHER SECONDARY SCHOOL, MEDAVAKKAM
}

\author{
*Ms. S.RathiDevi
}

\section{INTRODUCTION}

\section{"Self esteem is the reputation we acquire with ourselves"}

Self-esteem is a term used in psychology to reflect a person's overall evaluation or appraisal of his or her own worth. Self-esteem encompasses beliefs and emotions such as triumph, despair, pride and shame. Self-esteem can apply specifically to a particular dimension or have global extent.

Adolescent is the transitional stage of physical and mental development generally occurring between puberty and legal adulthood, but largely characterized as beginning and ending with the teenage stage. Development depends primarily upon what they do. And while adolescence is a stage at which they are neither a child nor an adult, life is definitely getting more complex as we attempt to find our own identity, struggle with social interactions, and grapple with moral issues. In that complexity of life that they are leading they will end in dependence or avoidance or failure. These all problems can lead them to have low self-esteem.

Many early theories suggested that selfesteem is a basic human need or self-esteem need, individuals will be driven to seek it and unable to grow and obtain self-actualization. Self-esteem is crucial and is a cornerstone of a positive attitude towards living. It is very important because it affects how they think, act and even how they relate to other people. It allows them to live life to their potential. Low self-esteem means poor confidence and that also causes negative thoughts which mean that they are likely to give up easily rather than face challenges. In addition, it has a direct bearing on their happiness and wellbeing. Thus, the researcher decided to assess the level of self esteem among adolescents.

\section{STATEMENT OF THE PROBLEM}

A study to assess the level of self-esteem among adolescents at Government Higher Secondary School, Medavakkam.

\section{OBJECTIVE OF THE STUDY:}

- To assess the level of self-esteem among adolescents.

- To identify the association between level of self-esteem and selected demographic variables

\section{OPERATIONAL DEFINITION:}

1. Self-Esteem. : It is the acceptance of adolescents of themselves for whom and what they are at any given time in their lives as assessed by the self-esteem rating scale. In the tool all the three aspects of self-esteem is being assessed. The three aspects of self-esteem are body image, perception and personal identity.

a) Body image: Adolescents are always concerned regarding their looks and they do lot of work outs to maintain their body fit.

b) Perception: The best way to express and interpret issues is exceptionally essential. If one really wishes to improve their determination energy as well as self-perception, they require a strong need which is able to show them their way. 
c) Personal identity: To bring positive changes to life, the essential elements are to know who they are and what their beliefs are.

2. Adolescents: It refers both girls and boys in the age group of 14 to16yrs.

\section{RESEARCH METHODOLOGY:} RESEARCH APPROACH:

A quantitative approach was used to assess the level the self-esteem among adolescents. Surveys are concerned with describing, recording analyzing and interpreting conditions that either exists or existed.

RESEARCH DESIGN: Descriptive Research Design

\section{VARIABLES:}

Research Variables : Level of self-esteem

Demographic variables: age, gender, year of study, birth order, parental Education, parental occupation, family income per month in (Rs), class of family and Previous information.

\section{POPULATION:}

The population of the study was all adolescents' students (both male and female) who had studied in Government High School, Medavakkam. It included students from VI standard to XII standard .The total population was 550

\section{SAMPLE:}

In the present study, the sample comprised of adolescents, who were in the age group between 10-16 years at Government High School, Medavakkam.

SAMPLE SIZE:

The samples selected for this study were 100 adolescents.

\section{SAMPLING TECHNIQUE:}

The sampling technique adopted was convenient sampling technique. The population of the adolescents of the whole school was 550 and sample size needed was 100 . As per the inclusion criteria, students from IX standard to XII standard who was present at the time of data collection and willing to participate in the study was selected

\section{DATA COLLECTION INSTRUMENTS}

It consists of section-A and Section-B

\section{SECTION A: GENERAL INFORMATION:-}

This section consisted of 10 items for obtaining information about the selected back ground factors of adolescents such as age, gender, year of the study, birth order, parental education, parental occupation, family income per month (Rs), any previous information, and if yes, then the source of information.

\section{SECTION B: RATING SCALE TO ASSESS} THE LEVEL OF SELF-ESTEEM:-

Rating Scale was prepared to assess the level of self-esteem among adolescents. It consisted of three sections; body image, perception and personal identity each having 10 subsections each and thus making a total of 30 items. Each item has four score options in which there are Often or a great deal will be allotted a score of 3 (three), Sometimes will be allotted a score of 2 (two), Seldom or occasionally will be allotted a score of 1(one) and Never or Not at all will be allotted a score of 0 (zero).

Score patterns of the tool as follows:

0-30 High self-esteem

31-60 Moderate self-esteem

61-90 Low self- esteem

\section{DATA COLLECTION PROCESS}

Data collection is the gathering of information needed to address a research problem. The study was conducted in Government High School, Medavakkam. Prior permission was obtained from the Principal. The data collection was done for a week in the school. A formal written 
permission was obtained from the authorities and data collection was done. Data was collected from 100 adolescents who fulfilled the inclusion criteria. Then the investigator assured that the information given by them will be kept confidential and consent was obtained from them.

\section{RESULTS}

The results showed the frequency and percentage distribution of socio-demographic variables of adolescents in which 32 of the respondents were in age group of 14 years, 18 were in age group of 15 years and 21 were in age group of 16years.55\%of them were males and the rest $45 \%$ were females. And the below table shows the level of self esteem of the adolescents.

TABLE1: Frequency and percentage distribution of level of self-esteem among adolescents

\begin{tabular}{|l|l|l|}
\hline $\begin{array}{l}\text { Study variable } \\
\text { Level of self esteem }\end{array}$ & Frequency & $\begin{array}{l}\text { Percentage } \\
(\%)\end{array}$ \\
\hline Low self-esteem & 18 & 18 \\
\hline Moderate self-esteem & 82 & 82 \\
\hline High self-esteem & 0 & 0 \\
\hline
\end{tabular}

The above table describes the frequency and percentage distribution of level of self-esteem among adolescents, which signifies that 82 of the adolescents possess moderate self-esteem, 18 of the adolescents possess low self-esteem and none of them were having high level of selfesteem.

It was found that there was no significant association between the level of self esteem and demographic variables. The researcher had a satisfying and learning experience throughout the study. The results of the study investigated the need for doing further research on adolescents.

\section{REFERENCES:}

Wikipedia the Free Encyclopedia. Self-esteem. 22Nov 2010. Available From: http://en.wikipedia.org/wiki/Self-esteem

Change Your World: Factoids :Girl Statistics and Studies :The Teen Media Juggling Act:2006:AvailableFrom:http://www.respect rx.com/archives.html.

Macmillan Dictionary for Students Macmillan, Pan.1981: 14, 456. Retrieved 2010- 715. AvailableFrom:http://en.wikipedia.org/wiki/ Adolescence\#cite_refMacmillan Dictionary for Students.

Wikipedia the Free Encyclopedia. Adolescence. 22Nov 2010 Available From: http://en.wikipedia.org/wiki/Adolescence.

Teens Health from Nemours. How can I improve my Self-Esteem .955-2010. Available 